\title{
"Domesticating the Foreign": An Introduction to the Concept of Localisation as a Strategy of Teaching Culture in Foreign Language Learning
}

\author{
Alfred Ndhlovu ${ }^{1}$ \\ ${ }^{1}$ University of Witwatersrand, Johannesburg, South Africa \\ Email: ndhlovualfa@gmail.com
}

DOI: $10.53103 /$ cjlls.v1i1.8

\begin{abstract}
Considering that cultures are rapidly undergoing evolution and that they have become more fluid than before, teaching culture in foreign language classes has become more challenging than before. First, this development challenges the traditional methods of teaching culture which have emphasized on imparting what is understood as a homogeneous target language culture to the learner without considering how this knowledge is transferred and how it benefits the learner community. Secondly, the multiplicity of cultures within the target language communities and their ever-changing nature in relation to the global world questions the very notion of what we call the "target language culture". With this in mind, it may be better to teach culture in foreign language classes from a cross cultural perspective and using the learner's cultural and local environment as a platform. This method is introduced in this article as localisation. This method of teaching culture can be considered most appropriate for a localised education system such as the tertiary education system in Zimbabwe, which is championed by the education 5.0 initiative, where every academic area including foreign language learning is expected to contribute to the development of local communities.
\end{abstract}

Keywords: Localisation, Modern Languages, Foreign Language Learning, Education 5.0

\section{Introduction}

This article introduces a method of teaching foreign language culture and Landeskunde (In German as foreign language classes) which considers the culture of the learner as a valuable resource. This method endeavours to familiarise learners with the target language cultural experience through relating it to their local cultural experience. Hence, it aims to "domesticate the foreign". The argument that is expressed here is that, if a foreign language culture is presented to the learner as a "foreign" or rather "alien" subject, it is likely to be stored in "foreign" spaces of their memory, where it is rarely retrieved and, therefore, in the long run, learners become less motivated to learn it and are likely to struggle to understand and to meaningfully incorporate it into their lives. Although it is common knowledge that "foreign languages" are referred to as such because they play less significant roles in the communities where they are learnt, encouraging learners to relate their cultural life to that of the target language community can help them understand the target language cultural life better. A comparative approach to the teaching of culture in a foreign language class is, therefore, likely to improve learners' "investment" in the target 
language culture and community, and thus promoting their inter-cultural competence. This is what the concept of Localisation attempts to achieve. This approach blends well the education 5.0 initiative which now guides the curriculum development of tertiary institutions in Zimbabwe. The education 5.0 initiative emphasises on the need for research to benefit local communities.

\section{Localisation}

The concept of localisation is not new in the academic field or in foreign language learning and teaching. However, it has been used in a slightly different manner compared to the way in which it is suggested and implemented in relation to the teaching of culture as is suggested in this article. For instance, in most scholarly work, it has been mainly used in relation to translation and digitization as in Schäler (2010), who defines it as the linguistic and cultural adaptation of digital content to the requirements and the locale of a foreign market. Hence, in its common usage, the term is used in relation to the interpretation of information, especially digital information. In this context, localisation is defined as a process of converting applications to operate in a specific cultural environment, which extends beyond the local language to aspects such as beliefs, customs, and ethics of a society (Soh et al., 2015). Soh et al. point out that localisation happens at two levels; at a linguistic level, where translation plays a key role in ensuring that resources are translated to reflect the local language, and at a cultural level where resources are explained in a way that reflects local customs. In this study, since the focus is on the teaching of culture in foreign language classes, localisation is understood in relation to the explanation and exploration of target language community cultural values in the context of the learner's cultural values, norms, and heritage than the interest in linguistic translation and digitization. In this context, localisation is, therefore, defined as the exploration and explanation of the target language cultural norms in the context of local norms of foreign language learners.

During the process of localising foreign languages which takes place mainly within the foreign language classroom, the target language content which is mainly provided through two sources; the learning material and the teacher is taught with reference to the learners' cultural content. Issues of target language culture are taught side by side with those that reflect the learners' society. Patterns are identified, and differences are highlighted. The understanding is that, through reference to familiar issues and creating a connection between the target language and the learner's society, learners are not only likely to be motivated but are also likely to (to use Norton's [2000] terminology) "invest" in their learning of a foreign language. What demonstrates this

\footnotetext{
${ }^{1}$ The construct of investment which has been described as a sociological construct as compared to that of motivation which is considered as a psychological construct (Norton, 2000), is proposed as a complimentary approach to that of motivation. While motivation deals with what moves individuals to study foreign languages, the concept
} 
investment is the ability for learners to extend the use of the localised target language information into their society. Hence, as Kam et al. (2007) also observe, localization of content is crucial to make the target language relevant to them and to encourage them to adopt it. Furthermore, for localisation to be successfully implemented, foreign language teachers need to be conversant with both the target language cultural values and the learner's local cultural norms and heritage.

There are two critical issues which need to be highlighted as a way of providing a background to Localisation; the need to consider exchange and negotiation as a crucial element in the teaching of culture studies and the realisation that cultural globalisation has transformed the teaching of culture. Localisation is a concept which is usually discussed alongside that of globalisation as reflected in a text by Ning and Yifeng (2008) titled Translation, Globalisation and Localisation: A Chinese Perspective. It is, therefore, a relevant strategy of teaching culture in foreign language learning in this era of cultural globalisation. Because of the fluidity of cultures as a result of globalisation, both the target language cultures, and local cultures of learner now share more components than before, hence making a rigid focus on the target language culture a less attractive endeavour.

Localisation is a concept which encourages a "double-view" approach to the study of culture in foreign language learning rather than the traditional approach which is based on the view that the learner must receive target language cultural information without negotiating on how such knowledge is transferred. Like many other globalised linguistic concepts such as identity, localisation considers the learning process as fluid and negotiable rather than rigid and rule oriented (as is the case with language learning). This is the very same notion that is central not only in Altmayer's (2017) discussion of Landeskunde in the global context but also (within the same text) in Pfleger's (2017) discussion of identity construction in a foreign language class (taking a class in Mexico as a case study). Pfleger, for instance, begins her discussion by acknowledging the fact that learning a new language leads to a reconstruction or rather renegotiation of one's identity. Hence, language learning is viewed as a transformative process.

What defines Localisation as a strategy of teaching Landeskunde is therefore, negotiation and the "double view" approach. Furthermore, several studies on culture in language learning have shown an interest not only in the acquisition of the target language culture by the learner but more on inter-cultural communication, a concern raised by scholars such as Heringer (2004). This interest is evident in Nguyen's (2017) analysis that: "cultural knowledge, awareness and competence" is inspired by Fenner's (2000) idea that language education should be to give learners opportunities to develop cultural knowledge, competence, and awareness of both the target culture and their own culture. (p. 147).

of investment seeks to unpack the connection between a learner's commitment to learn a language and the social conditions that are usually mirrored through the classroom and the larger target language community. 
However, despite this analysis by Nguyen, traditional methods of teaching foreign languages have placed little concern on the significance of the learner's culture and thus promoting a "single-view" approach rather than a "double-view" approach. Klein's (2004) study on how US-high school foreign language teachers (two French and two German teachers) integrated culture in their classes demonstrated that an intercultural and comparative approach which thrives on the "double-view" is employed (non-procedurally) by some foreign language teachers. Localisation is also related to what Nguyen terms a "process-oriented culture" approach. According to him, this "process-oriented culture" allows "students to see and experience another culture, to make comparisons with their own culture, and to develop an insider's view of the target language without actually travelling to the target culture" (p. 149). Learners' awareness of the target language culture and the source culture are also found in Brooks-Lewis' (2014) qualitative action-research study where she designed and applied a special introductory English course based on inter-cultural communication and awareness for her adult learners in Mexico. The learner participants of the study believed that comparing the English culture with their own culture helped them to see "real" people speaking the target language and to be aware of how culture affected individuals' thinking. Hence, as Ahmed et al observe, inter-cultural competence has recently become one of the main components to be taken into consideration when teaching foreign languages. Drawing on and motivated by Heringer's (2004) concept of "rich points" of culture, Ahrens (2006) also outlines the importance of a situational and learner-oriented teaching of culture (p.13):

I always draw a comparison with Zimbabwe, we refer to the Independence Bridge across the road to the airport, to the National Gallery in Julius Nyerere and to President Mugabe's visit to Malawi where a highway was called after him. This brings us to German Motorways that are numbered and headed with letters A and/ E. The E leads us the map of Europe. (sic).

In discussions on the impact of cultural globalisation in the teaching of culture in foreign language learning, one can even talk of a "multi-view" approach, since multiple cultures around the globe now share more characteristics than before, thus making possible multiple cross referencing when teaching culture.

Furthermore, Localisation can be considered as an appealing approach to teach culture in foreign language learning especially considering that target language communities usually do not have a homogeneous cultural structure. If cultures of the target language communities were uniform, knowledge of these cultures would have been taught to foreign language learners without much complexity. However, the existence of subcultures and regional cultures (such as Bavarian culture in Germany) makes this transfer a complicated matter. Hence, a comparative approach based on a compromise (negotiation) might be a progressive approach to the teaching of culture in foreign language learning. In the context of teaching culture in general, Nguyen 
(2017) notes the problems that may be created by the multiplicity of cultural categories. According to him (p.146):

Language education researchers have classified different types of cultural contents in language lessons to suit the purposes of their study. Kramsch (1995), for example, discusses three different "links" between language and culture. Universal links imply the culture that can be shared by various language speakers across social and national boundaries. National links refer to the cultures separated by the national boundaries such as French "civilization", German "Landeskunde" or English "culture".

In addition, Nguyen just like Altmayer (2017), adds another problematic category of "international or global culture" (p. 146). Quoting Matsuda (2012), Nguyeni defines international culture as including "various cultures from various parts of the world, or cultural topics that are of concern to the global society" (p. 146). If cultures are becoming more globalised, more is now shared and negotiated than before. Hence the current interest in the concept of "cultural globalisation" (see Altmayer, 2017).

In the context of teaching Landeskunde in German as foreign language (GFL) classes and basing her observations on the 1976 film "Shirins Hochzeit", Albrecht (2016) has raised similar concerns, arguing that German culture is no longer a homogeneous society as it was in the 1950s (where foreigners accounted for only one percent of the population) but can be described as multicultural and complex. She argues against what she terms an "essentialist view of German culture" and harmonized narratives revolving around the central idea that German people assume and believe in the "cultural homogeneity" of their country. She argues that these narratives not only essentialize the very groups of people they criticize but also create a false construct of culture that inaccurately represents the intricate dynamics of German society. According to her, to claim an "essentialist view of German culture" evokes notions of a cultural essence within the German people and notions of permanence, motionlessness, and inalterability. At a time of cultural globalisation, a state of cultural "inalterability" is not sustainable.

Following this situation, where a "single-view" approach of teaching culture is losing ground, a strategy of teaching Landeskunde that thrives on a "double-view", or "multi-view" approach can be considered suitable for the GFL classes. After-all, such a strategy cannot only be considered learner-oriented but also as an appropriate platform of integrating a multicultural and inter-cultural understanding of culture in foreign language learning. Localisation can also be an appropriate platform of (to use Simone Heine's [2017] terminology) "managing diversity". This diversity can be well documented by an extract taken (see Figure 1) from a Landeskunde textbook by Luscher, (2009). It is as if Luscher is asking the question: how can you say you are German, when almost everything in your life is foreign? 


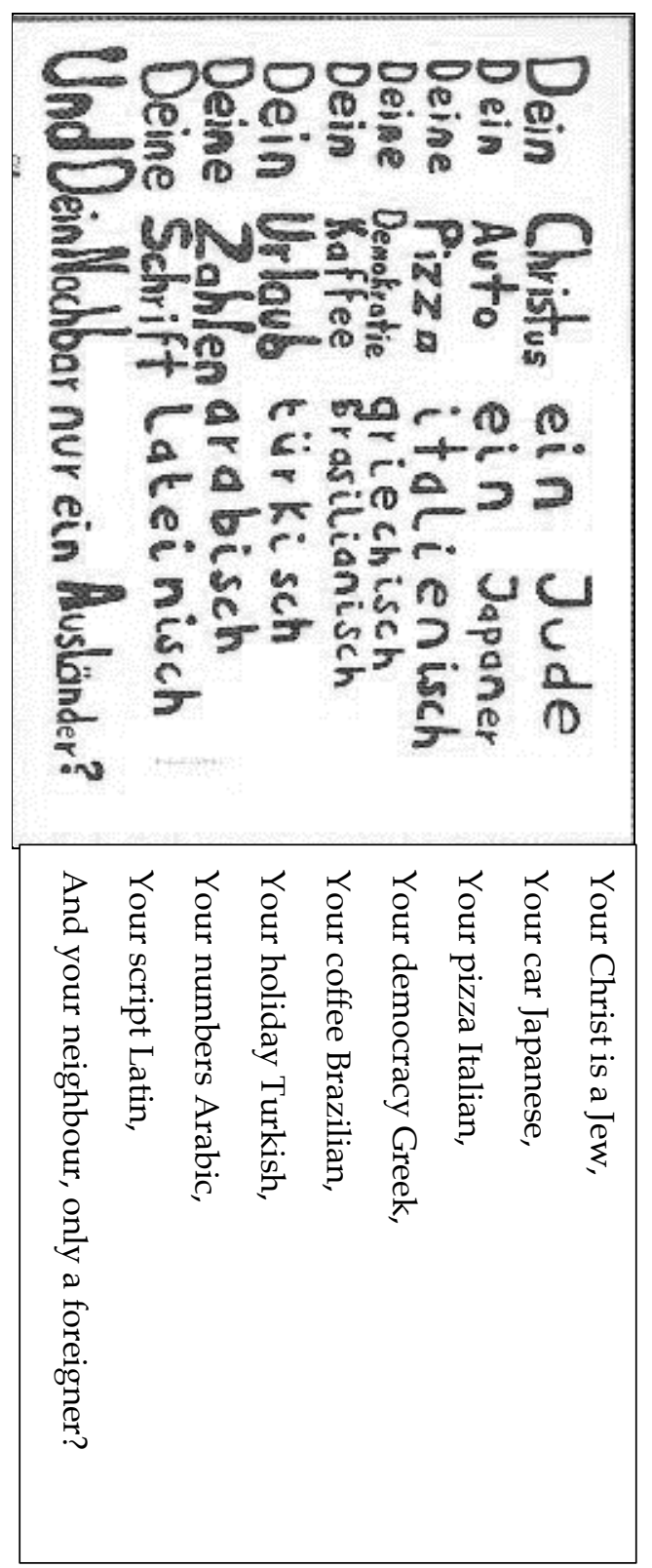

Figure 1: Multiculturalism in Germany today (taken from Luscher, 2009, p. 7) and translated by AN

\section{Education 5.0 in Zimbabwe}

Zimbabwe is one of the few nations in Africa which have considered the prospects of localisation at a time when most are either preferring to stick to colonial perspectives to education and curriculum development or adopting what they understand as "global" standards of curriculum development. The Zimbabwean government has supported the education 5.0 initiative which is a development from the 
3.0 adopted from the colonial government. The 3.0 focused on three areas namely teaching, research, and community service. However, in the "heritage-based" education 5.0 initiative, two more areas of focus have been added namely innovation and industrialisation. These two new areas of focus can now enable research to benefit the Zimbabwean community first and perhaps endeavour to fulfil global interests last. In its restructuring of the tertiary education system in Zimbabwe, the ministry of higher education has emphasized on the importance of adhering to the 5.0 model. This has left various university faculties and academic departments under pressure of shifting focus from "research for its own sake" to research for the benefit of the local communities of Zimbabwe. The departments of foreign language learning are not spared of this need to be "relevant". In this situation, the great question of the day is how can foreign languages benefit local communities when most learners are motivated to learn them to be part of the target language communities abroad and when most able-bodied Zimbabweans are eager to cross borders to seek better opportunities elsewhere? At least in the teaching of culture in foreign languages, the concept of localisation, therefore, is proposed as a method of teaching foreign languages which places emphasis on the need to teach target language culture to benefit learners, their culture, and their communities.

\section{Conclusion}

Considering that cultures are rapidly undergoing evolution and that they have become more fluid than before, trying to maintain a "single" view of teaching cultural studies in foreign language learning classes can be problematic. What is considered "French" or "German" now needs to be considered in the context of global interaction. It, therefore, now makes more sense to relate what is considered as the target language culture to not only the global world but most importantly to the immediate environment of the foreign language learner. Localisation, therefore, encourages "foreign" target language cultural knowledge to be brought to learners' local environment rather than the learner having to "travel" to a "foreign" culture to experience it and leave it there. The hypothesis is that when localised, the target language cultural knowledge becomes part of the learner's local cultural experience. It, therefore, becomes a possible valuable resource in the evolution of the learner's local culture. This method of teaching culture can, therefore, be considered appealing to a localised education system such as the tertiary education system in Zimbabwe which is guided by the education 5.0 initiative.

\section{References}

Ahmed, S. T. S, Qasem, B. T. A., \& Pawar, S. V. (2019). Integrating culture into EFL teaching: A study of Yemeni EFL teachers' perceptions and actual practices. Language in India, 19(4), 1-16.

Ahrens, E. R. (2006). Intercultural communication: A concept for teaching. A paper presented at a public Lecture (Faculty of arts, University of Zimbabwe in Harare, Zimbabwe. Ahrens handle: http://hdl.handle.net/10646/312. 
Albrecht, M. (2016). On the invention of an "essentialist view of culture": Thinking outside the prevalent cultural studies discourse on culturally and ethnically heterogeneous Germany. ZS: New Issue German Quarterly, 89(4).

Altmayer, C. (2017). Landeskunde im globalisierungskontext: Wozu noch kultur im daf-unterricht? In Haase and Höller (Eds.). 2017. Kulturelles lernen im DaF/DaZ-unterricht: Paradigmenwechsel in der landeskunde. Göttingen: Universitätsverlag Göttingen, 3-22.

Brooks-Lewis, K. A. (2014). Adult learners' perceptions of the significance of culture in foreign language teaching and learning. Journal of Education and Training Studies, 2(2), 9-19.

Kam, M., Ramachandran, D., Devanathan, V., Tewari, A., \& Canny, J. (2007). Localized Iterative Design for Language Learning in Underdeveloped Regions: The PACE Framework. Retrieved on 19 December from https://www.google.co.za/search?q=Localized+Iterative+Design\&client=msoperamini\&channel=new\&gws_rd=cr\&dcr=0\&ei=Yiw5WtD6FIOzkwXH15e 4CQ.

Klein, F. M. V. (2004). Culture in the foreign language classroom: Teachers' beliefs, opportunities and practice. (Unpublished $\mathrm{PhD}$ Thesis), University of Minnesota, Minneapolis.

Luscher, R. (2009). Von der wende bis heute: Landeskunde Deutshland. München: Verlag für Deutsch.

Nguyen, T. T. T. (2017). Integrating culture into language teaching and learning: Learner outcomes. The Reading Matrix: An International Online Journal, $17(1), 145-155$.

Ning, W., \& Yifeng, S. (2008). Translation, globalisation and localisation: A Chinese perspective. Clevedon: Multilingual Matters.

Norton, B. (2000). Identity and language learning: Gender, ethnicity and educational change. Essex: Pearson Education Limited.

Pfleger, S. (2017). Identitätskonstruktion im fremdsprachenunterricht: Ein pilotprojekt daf in mexiko. in haase and höller (eds.). 2017. kulturelles lernen im DaF/DaZUnterricht: Paradigmenwechsel in der Landeskunde. Göttingen: Universitätsverlag Göttingen, 23-38.

Schäler, R. (2010). Localisation and translation. In Handbook of Translation, (I), 209214.

Soh, M., Kouesso, R. J., \& Fotso, L.P. (2015). Localisation of information and communication technologies in Cameroonian languages and cultures: Experience and issues. (IJACSA) International Journal of Advanced Computer Science and Applications, 6(12), 295-300. 